East African Medical Journal Vol. 77 No. 2 February 2000

NATURALISTIC STUDY OF OLANZAPINE IN TREATMENT-RESISTANT SCHIZOPHRENIA AND ACUTE MANIA, DEPRESSION AND OBSESSIONAL DISORDER

J. U. Ohaeri, MD, Professor of Psychiatry, College of Medicine, University of Ibadan, Ibadan, Nigeria.

Request for reprints to: Dr. J. U. Ohaeri, Consultant Psychiatrist and Medical Superintendent, St. Giles Psychiatric Hospital, Reservoir Road, P.O. Box 105, Suva, Fiji Islands.

\title{
NATURALISTIC STUDY OF OLANZAPINE IN TREATMENT-RESISTANT SCHIZOPHRENIA AND ACUTE MANIA, DEPRESSION AND OBSESSIONAL DISORDER
}

\section{J. U. OHAERI}

\begin{abstract}
Background: Whereas the Fiji government provides all aspects of mental health care services free of charge to its citizens, many schizophrenics have failed to respond to classical antipsychotic drugs.

Objective: To assess the efficacy and safety of olanzapine among various patients with severe psychiatric disorders.

Setting: Naturalistic setting.

Design: Descriptive study.

Measurements: Outcome was based on reduction of symptoms on the PANSS $(\geq 40 \%)$ and CGI shift to 1-3.

Subjects: The were 64 patients (30 males) aged 17-77 years. Thirty six $(56.3 \%)$ had schizophrenia, eight mania, ten severe depression, four obsessive compulsive disorder (OCD), one each had schizo-affective and delusional disorders, while the remaining had chronic brain diseases.

Results: At weeks 3, 8,12, the proportion of subjects with $40 \%$ improvement was $60.6 \%$, $79.9 \%$, and $76.8 \%$, respectively. Positive and negative symptoms improved. Thirteen $\mathbf{4} 48.1 \%)$ of the 27 long-stay treatment - resistant schizophrenics achieved clinical recovery at eight weeks. All with primary diagnosis of severe depression and mania achieved full clinical recovery (mostly within two weeks). Two OCD cases achieved clinical recovery at week eight.

Conclusion: Olanzapine was safe for all categories of patients. There was not a single case of extrapyramidal reaction among subjects who did not have it pre-treatment; and the drug was safe in a suicidal overdose of $205 \mathrm{mg}$. Most patients experienced weight gain; two adolescent girls had temporary amenorrhoea and one subject had transient rise in liver transaminases which normalised without discountinuing the drug.
\end{abstract}

\section{INTRODUCTION}

After over four decades of clinical experience of use of the classical or typical antipsychotic drugs, psychiatrists are challenged by the fact that $30-50 \%$ of schizophrenics do not significantly benefit from these drugs, and there are adverse effects, some of which could be irreversible(1). This situation serves as a compelling motivation to seek treatment alternative.

Clozapine was reintroduced into the psychopharmacology market in the late 1980s as the first to fulfill the characteristics of what has recently become known as "atypical antipsychotic" drugs, namely, broader efficacy than the older drugs; a lower incidence of extrapyramidal symptoms; minimal perturbation of prolaction levels; and therapeutic efficacy among non responders to conventional neuroleptics(2).
Such a therapeutic advance should have substantial relevance for the societal costs, personal suffering and mortality that characterise schizophrenia(3) .

The problems with clozapine are, the danger of potentially fatal leucopaenia, the significant lowering of seizure threshold and sialorrhoea.

In the Fiji Islands, a South Pacific developing country of some 800,000 mixed race people, of whom the indigenous race claims Tanzanian (African) origin, mental health care delivery is free, and the classical antipsychotic drugs are abundantly available. By early 1997, the major challenge to clinical psychiatry was that at least one - third of admissions in the nation's only psychiatric hospital (190 beds) were neuroleptic treatment - resistant long-stay schizophrenics. The Ministry of Health therefore agreed to purchase some quantity of the new atypical antipsychotic drug, Olanzapine (OLZ), for a 6-8 week efficacy and 
safety trial, with a view to seeing whether a significant proportion of these schizophrenics could achieve enough remission of symptoms to be discharged home.

OLZ is a thienobenzodiazepine structurally related to clozapine, with relatively greater binding affinity for 5HT2 compared to D2 receptors. The compound has a broad receptor profile, that is, it is pleotropic.

As at February, 1995, OLZ had been investigated in 50 studies in 22 countries, resulting in a total of 3139 persons having been exposed to at least one dose of OLZ(4).

Since then, there has been a plethora of publications, making OLZ one of the most rigorously investigated of new drugs(4-8). All these studies were unanimous in upholding the credentials of OLZ as fulfilling the requirements of belonging to the group of "atypical" antipsychotic drugs(9). In addition, evidence has now emerged indicating that the drug also has impressive antimanic(10) and direct antidepressant effects(11,12), especially among schizophrenics(3), while improving cognitive functioning(11). OLZ has been shown to be efficacious in treatment - resistant schizophrenics $(12,13)$, especially at 40-60 mg daily dosage(14).

This is a general descriptive study, not a controlled double - blind study. The aims of the study were, to assess the efficacy and safety of OLZ among the variety of patients with severe psychiatric states that patronise our centre and were treated in the usual clinical care (naturalistic) setting. Although the initial mandate concerned treatment - resistant long-stay schizophrenics, other patients were included with severe depression and suicidal behaviour who either refused electroconvulsive therapy (ECT) or had heart disease; as well as manic patients who had extrapyramidal reactions to classical neuroleptics and obsessional (OCD) patients who had failed to respond to standard treatments.

The naturalistic setting of the study allowed for the inclusion of such a wide variety of patient groups.

\section{MATERIALS AND METHODS}

Location and instruments: The study took place at St. Giles Psychiatric Hospital, Suva, Fiji, from late January, 1997 to midApril, 1998. All the subjects involved in the study were the author's patients and were all personally assessed by him at intake, and then at weeks 3, 6, 8, 10 and 12 using the following instruments: (i) The 30-item Positive and Negative Syndrome Scale (PANSS) (15), rated along a scale of severity that ranged from 1 (normal) to 7 (extreme). This instrument contains the main symptoms of schizophrenia and can be used to assess severity of mania, depression, anxiety and OCD; (ii) the Clinical Global Impression (CGI) scale, for a global assessment of severity of illness at intervals, also rated on a 7-point scale of, 1 (normal), 2 (minimal or borderline ill), 3 (mild), 4 (moderately ill), 5 (markedly ill) 6 (severely ill) to 7 (among the most extremely ill patients) (16); (iii) Parkinsonism (17), akathisia (18) and tardive dyskinesia (16), were also assessed; (iv) The Hamilton Depression Rating Scale (HDRS) was applied to 10 subjects with a primary diagnosis of severe depression; and one with obsessive compulsive disorder (OCD); (v) side effects were specifically enquired into; (vi) haematological and biochemical tests, pre - olz, at three weeks and six; (vii) the Yale-Brown Obsessive Compulsive Scale (Y - BOCS) was applied to four subjects with OCD, at some time after olz had been initiated.

Subjects: There were three broad groups of patients, namely: (i) twenty seven long-stay treatment resistant schizophrenics; (ii) fifteen treatment resistant patients who had spent less than one-year in hospital or were out-patients and; (iii) twenty two acutely ill subjects (including schizophrenics, depressed and manic patients) who had not yet received adequate neuroleptic treatment for the current episode. All patients and relatives freely consented to participate in the study after the objectives were explained to them by the author.

Definition of treatment resistance and efficacy measures: A neuroleptic treatment resistant schizophrenic (NTRS) was operationally defined as one who had failed to respond to at least $800 \mathrm{mg}$ chlorpromazine equivalent daily dosage for at least the past one year. Efficacy of treatment was defined by the following measures: a CGI scale score of 2 or 3 for the NTRS cases; and one or two for all the acutely ill cases; for all cases, a forty percent reduction in PANSS score by the sixth to eighth week of treatment (3); for the depressed patients, a HDRS Scale Score of less than 10 by the sixth week of treatment and; for the OCD cases, an admission by the patient of significant freedom from symptoms.

Dosage: The initial starting daily dosage for NTRS cases, acutely ill schizophrenics and manic subjects was $15-20 \mathrm{mg}$. In addition, six NTRS received 30mg daily for four weeks, after a 12 -week period of $20 \mathrm{mg}$ in which they had not shown significant improvement. Patients with severe depression were treated mostly with $10-15 \mathrm{mg}$ nightly dose. The OCD cases received $5-15 \mathrm{mg}$ daily.

\section{RESULTS}

Demographic characteristics: The sample consisted of 30 males (mean age, $39.6 \pm 13.4$ ) and 34 females (39.2 \pm 14.3 years) (age range, 17-77, mean, $39.4 \pm 13.8 \mathrm{yrs}$ ). There were 26(40.6\%) indigenous Fijians and 31(48.4\%) Indians, with other races (Chinese, European) constituting $9.9 \%$ of the sample.

Clinical characteristics: Subjects fulfilled the American DSM-IV criteria for the diagnosis of schizophrenia (36 or $56.3 \%$ ), Bipolar I disorder, manic phase ( 8 or $12.5 \%$ ), severe depression (10 or $15.6 \%$ ); OCD ( 4 or $6.25 \%$ ); while one each $(1.6 \%$ x 2 ) had schizoaffective disorder and delusional disorder, respectively. The remaining subjects had brain diseases, in addition to severe mental disorder. This group included an elderly (77-yr old) lady who had previously suffered two episodes of cerebrovascular accident; two subjects who had frequent episodes of convulsions from childhood; and one subject who had mild mental retardation. One depressed patient was on follow up treatment for heart failure.

There were 51(79.7\%) in-patients, and $13(20.3 \%)$ out-patients.

On the whole, 27 (43.8\%) subjects were long-stay neuroleptic treatment-resistant schizophrenic cases, having been continuously on admission for over one year and experienced no improvement inspite of adequate 
neuroleptic treatment and ECT. Another 15 (21.9\%) subjects were also treatment resistant (NTR) but were either out-patients or had stayed in hospital for less than one year. This group included schizophrenics, OCD cases, and one epileptic and mental retard with schizophrenic symptoms. The remaining 22 (34.4\%) subjects were acutely ill, had not been exhaustively treated with the older methods and included acutely ill schizophrenics, the affective disorder cases, two OCD cases and delusional disorder.

The hospital provided the drug free for $33(51.6 \%)$ subjects, while relatives bought it for $24(37.5 \%)$. For the remaining seven (10.9\%), hospital supplemented the supply from relatives.

Efficacy measures: Number of subjects remaining in the trial: Sixty (93.8\%) completed eight weeks of active phase of treatment. The remaining four consisted of three depressed patients who had responded very well and one non-responding acute schizophrenic whose relatives
$43.6 \%$ achieved this level of improvement at the sixth week; while from the eighth week onward, the median and mode scores for percentage improvement were consistently above 50.0.

Change in Psychopathological Symptoms Scores (PANSS): It is to be noted that, as conceptualised, negative symptoms are features of schizophrenia; and while severely depressed patients would also have a lot of these symptoms, they do not characterise mania and OCD. Schizophrenics and the depressed showed highly significant (almost one - half shifts in mean scores) changes in negative symptoms scores from the third week of assessment; and this was maintained throughout the active phase of the study (e.g for schizophrenics, from 26.7 through 15.2 at week 3 , to 12.6 at week 10; for depressed patients, from 36.4, through 12.6 at week 3 , to 9.0 or no pathology at week 10). Similar sustained remarkable reductions in positive symptoms scores were also evident.

Table 1

Overview of total PANSS scores at intervals

\begin{tabular}{|c|c|c|c|c|c|c|}
\hline No. & Interval of assessment & Range & Mean & SD & Median & Mode \\
\hline 1. & Pre-OLZ $(\mathrm{N}=64)$ & $44-158$ & 86.35 & 28.7 & 79.0 & 57.0 \\
\hline 2. & Week $3(\mathrm{~N}=64)$ & $30-95$ & 46.3 & 17.2 & 39.5 & 30.0 \\
\hline 3. & Week $6(\mathrm{~N}=62)$ & $30-93$ & 40.5 & 15.6 & 32.0 & 30.0 \\
\hline 4. & Week $8(\mathrm{~N}=60)$ & $30-95$ & 40.0 & 15.6 & 31.0 & 30.0 \\
\hline 5. & Week $10(\mathrm{~N}=51)$ & $30-101$ & 38.8 & 14.1 & 31.0 & 30.0 \\
\hline 6. & Week $12(\mathrm{~N}=43)$ & $30-101$ & 40.8 & 16.2 & 32.0 & 30.0 \\
\hline 7. & Week $14(\mathrm{~N}=25)$ & $30-66$ & 36.9 & 11.6 & 31.0 & 30.0 \\
\hline 8. & Week $16(\mathrm{~N}=25)$ & $30-62$ & 35.9 & 10.8 & 31.0 & 30.0 \\
\hline 9. & Week $18(\mathrm{~N}=15)$ & $30-56$ & 34.0 & 8.4 & 31.0 & 31.0 \\
\hline
\end{tabular}

withdrew consent. Majority completed at least 12 weeks of trial.

Total PANSS Scores: Overview: Table 1 shows that when taken as a whole, this group of patients showed a rapid reduction of psychopathological symptoms within three weeks of treatment, with almost a halving of the group's total mean score (86.3 - 46.3). Subsequently, the mean score fell fairly consistently to 40.8 at week 12 . The median and mode show that from the sixth week of trial, the commonest individual scores (30-32) were rather close to the minimum score on the PANSS.

From the third week, the proportion of subjects with over $40 \%$ improvement in psychopathology increased from $60.6 \%$ through $79.9 \%$ at the eighth week and was $76.8 \%$ at the twelfth week. Even when we use the more conservative yardstick of $50 \%$ improvement we find that
From the third week, $58.4 \%$ of schizophrenics had experienced at least $40 \%$ reduction in PANSS scores; and by the tenth week, the proportion experiencing over $40 \%$ of improvement had increased to $74.1 \%$. When we use the more conservative yardstick of $50 \%$ of reduction of symptoms, the proportion of schizophrenics experiencing this level of improvement increased from $35.2 \%$ at the third week, to $53.2 \%$ at the tenth week. All the manic and depressed patients experienced over $40 \%$ improvement from week three.

Significant differences in psychopathological symptom scores: At the pre-olz level, the tendency for higher symptom severity among depressed patients (93.6 $\pm 30.2)$ and schizophrenics $(84.3 \pm 29.9)$ than manic and OCD cases did not reach statistical significance $(\mathrm{F}=2.0, \mathrm{p}$ $=0.07)$. But at the third week, depressed patients showed 
significantly higher percentage improvement than schizophrenics, for total PANSS symptoms scores change $(\mathrm{F}=2.4 ; \mathrm{p}=0.03)$ and negative symptoms scores change $(\mathrm{F}=3.8, \mathrm{p}=0.0019)$. Of the four OCD cases, at the eighth week, two had achieved full clinical recovery, one had moderate severity of symptoms $(\mathrm{CGI}=4)$, while one was treatment resistant.
Change in Psychopathological Symptom Scores (PANSS) for Neuroleptic Treatment Response Groups (Tables 2 and 3): The three neuroleptic treatment response groups showed rapid reduction of symptoms severity.

Table 2 shows that acutely ill patients had much higher proportions of subjects with over $40 \%$ improvement in symptoms, with this trend reaching significance at the third and sixth weeks. $(F=8.2, p=0.0007)$. From the

Table 2

Overview of percentage improvement in psychopathological symptoms scores (ie decrease in PANSS/BPRS scores) at intervals of assessment for neuroleptic treatment response groups

\begin{tabular}{|c|c|c|c|c|c|c|c|c|c|c|}
\hline \multirow{2}{*}{$\begin{array}{l}\text { Interval of } \\
\text { assessment }\end{array}$} & \multirow{2}{*}{$\begin{array}{l}\text { Neuroleptic response } \\
\text { Group(No. of subjects) }\end{array}$} & \multirow{2}{*}{$\begin{array}{l}\% \\
\text { Range }\end{array}$} & \multicolumn{8}{|c|}{ Change in PANSS score } \\
\hline & & & $<0$ & $1-19$ & $20-25$ & $26-29$ & $30-39$ & $40-49$ & $50-59$ & $>60$ \\
\hline \multirow[t]{3}{*}{ At Week 3} & $\begin{array}{l}\text { 1. Long stay resistant } \\
(\mathrm{N}=27) \\
\text { 2. Short stay resistant }\end{array}$ & -5 to 68 & $1(3.7)$ & $4(14.8)$ & $1(3.7)$ & $1(3.7)$ & $5(18.5)$ & $8(29.6)$ & $4(14.8)$ & $3(11.1)$ \\
\hline & $(\mathrm{N}=15)$ & -5 to 65 & $1(6.7)$ & $1(6.7)$ & - & $2(13.3)$ & $1(6.7)$ & $4(26.7)$ & $4(26.7)$ & $1(6.7)$ \\
\hline & 3. Acutely ill $(\mathrm{N}=22)$ & $0-74$ & - & - & - & - & $3(13.6)$ & $5(27.3)$ & $9(40.9)$ & $5(27.3)$ \\
\hline \multirow[t]{3}{*}{ At Week 6} & 1. Long Stay $(\mathrm{N}=27)$ & -3 to 75 & $1(3.7)$ & $2(7.4)$ & $1(3.7)$ & $1(3.7)$ & $4(14.8)$ & $8(29.6)$ & $5(18.5)$ & $5(18.5)$ \\
\hline & 2. Short Stay $(\mathrm{N}=14)$ & $0-68$ & - & - & - & $1(7.1)$ & $1(7.1)$ & $4(28.6)$ & $3(21.4)$ & - \\
\hline & 3. Acutely ill $(\mathrm{N}=22)$ & $0-78$ & - & - & - & - & - & $4(18.2)$ & $7(31.8)$ & $10(45.5)$ \\
\hline \multirow[t]{3}{*}{ At Week 8} & 1. Long Stay $(\mathrm{N}=27)$ & -3 to 74 & $1(3.7)$ & $2(7.4)$ & - & - & $6(22.2)$ & $6(22.2)$ & 7 (28.9) & $5(18.5)$ \\
\hline & 2. Short Stay $(\mathrm{N}=13)$ & $0-77$ & - & - & - & 1.(7.7) & $1(7.7)$ & $3(23.0)$ & $2(15.4)$ & 6. (46.2) \\
\hline & 3. Acutely ill $(\mathrm{N}=20)$ & -4 to 77 & $1(5)$ & - & - & - & - & $2(10)$ & $8(409)$ & $9(45)$ \\
\hline \multirow[t]{3}{*}{ At Week 10} & 1. Long Stay $(N=26)$ & -1 to 79 & $1(3.8)$ & $1(3.8)$ & - & - & $5(19.2)$ & $7(26.9)$ & $5(19.2)$ & $7(26.9)$ \\
\hline & 2. Short Stay $(\mathrm{N}=10)$ & $0-77$ & - & - & - & $1(10)$ & $1(10)$ & $1(10)$ & $2(20)$ & $5(50)$ \\
\hline & 3. Acutely ill $(\mathrm{N}=15)$ & $0-78$ & - & $1(6.7)$ & - & - & - & - & $6(40)$ & $8(53.3)$ \\
\hline \multirow[t]{3}{*}{ At Week 12} & 1. Long Stay $(\mathrm{N}=22)$ & -1 to 79 & $1(4.5)$ & $1(4.5)$ & - & - & $5(22.7)$ & $6(27.3)$ & $5(22.7)$ & $4(18.2)$ \\
\hline & 2. Short Stay $(N=9)$ & $0-75$ & - & - & - & $1(11.1)$ & $1(11.1)$ & $1(11.1)$ & $2(22.2)$ & $4(44.4)$ \\
\hline & 3. Acutely ill $(\mathrm{N}=12)$ & $0-77$ & - & $1(8.3$ & - & - & - & - & $5(41.7)$ & $6(50.0)$ \\
\hline
\end{tabular}

Table 3

Response to olanzapine according to neuroleptic treatment response status (NTRS) at intervals of assessment, using the clinical global impression scale

\begin{tabular}{|c|c|c|c|c|c|c|c|c|}
\hline $\begin{array}{l}\text { Interval of } \\
\text { assessment }\end{array}$ & NTRS status & $\begin{array}{l}\text { Clinical } \\
1\end{array}$ & $\begin{array}{l}\text { Global } \\
2\end{array}$ & $\begin{array}{l}\text { Impression } \\
3\end{array}$ & 4 & 5 & 6 & 7 \\
\hline \multirow[t]{3}{*}{ A. Pre-OLZ } & 1. Long stay resistant $(\mathrm{N}=27)$ & - & - & - & - & $4(14.8)$ & $4(14.8)$ & $19(70.3)$ \\
\hline & 2. Short stay resistant & - & - & - & $2(13.3)$ & $4(16.7)$ & $6(40.0)$ & $6(40.0)$ \\
\hline & 3. Acutely III ( $\mathrm{N}=22)$ & - & - & - & $3(13.6)$ & $6(27.3)$ & $4(18.2)$ & $9(40.9)$ \\
\hline \multirow[t]{3}{*}{ B. Week 3} & 1. Long stay $(\mathrm{N}=27)$ & $2(7.4)$ & $6(22.2)$ & $6(22.2)$ & $6(22.2)$ & $4(14.8)$ & $3(11.1)$ & - \\
\hline & 2. Short stay $(\mathrm{N}=15)$ & $4(26.7)$ & $1(6.7)$ & $3(20.0)$ & $5(33.3)$ & - & $1(6.7)$ & $1(6.7)$ \\
\hline & 3. Acutely ill $(\mathrm{N}=22)$ & $8(36.4)$ & $7(31.8)$ & $6(27.3)$ & - & $1(4.5)$ & - & - \\
\hline \multirow[t]{3}{*}{ C. Week 6} & 1. Long stay $(\mathrm{N}=27)$ & $4(14.8)$ & $9(33.3)$ & $2(7.4)$ & $5(18.5)$ & $4(14.8)$ & $1(3.7)$ & $2(7.4)$ \\
\hline & 2. Short stay $(N=14)$ & $5(35.7)$ & $4(28.6)$ & $2(14.2)$ & $2(14.2)$ & - & $1(7.1)$ & - \\
\hline & 3. Acuteiy ill $(\mathrm{N}=22)$ & $19(86.4)$ & $2(9.1)$ & - & $1(4.5)$ & - & & - \\
\hline \multirow[t]{3}{*}{ D. Week 8} & 1. Long stay $(\mathrm{N}=27)$ & $7(25.9)$ & $6(22.2)$ & $5(18.5)$ & $3(11.1)$ & $4(14.8)$ & - & $2(7.4)$ \\
\hline & 2. Short stay $(N=13)$ & $4(30.7)$ & $6(46.2)$ & - & $2(15.4)$ & - & $1(7.7)$ & - \\
\hline & 3. Acutely ill $(\mathrm{N}=20)$ & $17(85.0)$ & $1(5.0)$ & $1(5.0)$ & - & - & & $1(5.0)$ \\
\hline \multirow[t]{3}{*}{ E. Week 10} & 1. Long stay $(\mathrm{N}=26)$ & $6(23.1)$ & $8(30.8)$ & $3(11.5)$ & $4(15.4)$ & $3(11.5)$ & - & $2(7.7)$ \\
\hline & 2. Short stay $(N=10)$ & $3(30.0)$ & $4(40.0)$ & - & $2(20.0)$ & - & $1(10.0)$ & - \\
\hline & 3. Acutely ill $(\mathrm{N}=15)$ & $13(86.7)$ & - & $1(6.7)$ & $1(6.7)$ & - & - & - \\
\hline \multirow[t]{3}{*}{ F. Week 12} & 1. Long stay $(\mathrm{N}=22)$ & $5(22.7)$ & $4(18.2)$ & $4(18.2)$ & $4(18.2)$ & $2(9.1)$ & $1(4.5)$ & $2(9.1)$ \\
\hline & 2. Short stay $(N=9)$ & $2(22.2)$ & $4(44.4)$ & - & $2(22.2)$ & - & $1(11.1)$ & - \\
\hline & 3. Acutely ill $(\mathrm{N}=12)$ & $10(83.3)$ & - & - & $1(8.3)$ & $1(8.3)$ & - & - \\
\hline
\end{tabular}


eighth week, however, although the long-stays had significantly higher PANSS and positive symptoms scores than the acutely ill at that point $(F=3.6, p=0.03)$, there was no significant differences in mean percentage reduction of all types of symptoms across the three groups, upto the twelfth week.

The tendency for the acutely ill to show higher mean reduction in symptoms severity than the short stays reached significance for positive symptoms at the third $(\mathrm{F}=4.8, \mathrm{p}$ $=0.01)$ and sixth weeks $(\mathrm{F}=4.1, \mathrm{p}=0.02)$

These trends are reflected in the changes of CGI (Table 3). Byy the eighth week $90 \%$ of the acutely ill had achieved CGI status of 1 or 2, while $66.6 \%$ and $76.9 \%$, respectively, of the treatment resistant long stays and short stays had shifted to CGI status of 1-3.

Improvement in Hamilton Depression Rating Scale scores at intervals: Olanzapine proved to be a highly potent and rapidly acting antidepressant drug, even though it is marketed as an antipsychotic drug.

There was a drastic reduction in mean HDRS scores from 31.5 (SD 6.2) at intake, through 4.9 (SD 7.2) at the second week, and 3.5 (SD 6.6) at the third week, to 1.8(SD 5.4 ) at the fourth week. The only patient who remained with any severe symptoms of depression after the fourth week was a treatment resistant obsessive compulsive patient. Highly significant improvement in depression scores evident at the second week $(63.6 \%$ had fully recovered and 3 or $27.3 \%$ others scored)(9-15), was improved upon at the sixth week when all the eight primarily depressed patients still remaining in the study had achieved full clinical recovery. It is to be noted that most of these patients had severe psychomotor retardation, with strong suicidal ideation.

In all these indices of efficacy, there were no significant racial differences in psychopathological symptoms scores at all the intervals of assessment.

Experience of effectiveness of drug dosages: It was found that, treatment resistant schizophrenics and manic subjects would require at least $20 \mathrm{mg}$ daily during the active phase of treatment. Of the treatment resistant schizophrenics, those who did very well (CGI, 1 or 2) would appear to require about $15 \mathrm{mg}$ daily, while those who responded at the CGI level of 3 or 4 would definitely require at least $20 \mathrm{mg}$ daily.

Of the six long-stay neuroleptic treatment cases who were tried on $30 \mathrm{mg}$ daily for four weeks, two showed no significant improvement, three showed remarkable improvement (CGI levels moved at least two points positively), while one subject (with mild mental retardation) only showed enhanced cognitive functioning and emotional warmth.

It appears, therefore, that the $20 \mathrm{mg}$ maximum dosage set by the manufacturers applies mainly to the acutely ill psychotic subjects. Certainly, the recommended $7.5 \mathrm{mg}$ daily, maintainance dosage is of no use to neuroleptic treatment resistant cases. Also the NTRS cases should be tried on at least $30 \mathrm{mg}$ daily before they can be pronounced as non-responding.
Patients who recovered from depression and OCD did quite well on a follow up dose of 5-10mg nocte daily dose.

Safety profiles: (i) Patients with epilepsy tolerated the drug without increase of seizure frequency. Patients who received OLZ in the two weeks after ECT, did not experience post- ECT seizure; (ii) One 52-year old man with heart failure and symptoms of severe depression, responded well to $10 \mathrm{mg}$ olz, without adverse ECG effects; (iii) One 25-year old man took 41 tablets of $5 \mathrm{mg}$ olz that is, $205 \mathrm{mg}$ in a suicidal bid. ECG showed no abnormal tracings, and there were no untoward effects; (iv) A 77year old lady who had had two episodes of CVA, developed disruptive symptoms of delusional disorder. She tolerated $10-15 \mathrm{mg}$ of olz very well and; (v) One 45-year old treatment resistant long-stay schizophrenic has had a psoriasis-like skin lesion for several years, which showed little or no response to treatment. While on OLZ only, there was remarkable improvement in his skin condition

Leucopaenia in two subjects. Pre-olz: The result of blood tests for two long-stay treatment resistant schizophrenics (one male, 74-year old and one female, 52year old) showed that they had very low white blood cell counts in the pre-treatment sample. The female also had anaemia and hepato-splenomegaly, while the old man had non- insulin dependent diabetes melitus. Repeated sampling for leucocyte count in the period of three months when they were on OLZ showed that, though they had no significant remission of psychotic symptoms, their leucocyte count actually improved significantly.

Extrapyramidal side effects: Two late middle aged ladies and one elderly man with Pre-Olz mild levels of tardive dyskinesia, experienced an intensification of their dyskinesia, and tremors when OLZ was commenced. But one 25-year old female with akathisia, was no longer experiencing it. None of the six subjects who received $30 \mathrm{mg}$ OLZ showed any side effects. Two subjects had grotesque abnormal body movements, ostensibly tardive dystonia from years of neuroleptic treatment. They had full clinical remission of psychosis and a significant reduction in abnormal movements.

In other words, inspite of the fact that patients did not receive concomitant anticholinergic medication, there were no extrapyramidal features among subjects who did not have them pre-olz.

Two girls (17 and 20 years) experienced amenorrhoea: For one of them (on $5 \mathrm{mg}$ olz) menstruation returned at the end of the third month while still on olz. For the second one (on olz 10mg) menstruation quickly returned when she stopped olz, as she had achieved full clinical recovery.

Weight gain was experienced by most patients, especially out-patients: Weight gain was usually evident at least by the sixth week of treatment. For the in-patients, the nurses controlled this problem by placing the patients on "reduction diet"; so that on the whole, the in-patients did not complain about weight gain. One tall athletic built young man's weight increased from $90 \mathrm{~kg}$ to $100 \mathrm{~kg}$ in three months of olz $10 \mathrm{mg}$ daily. 
Only one 36-year old lady showed mildly elevated liver enzymes level at the third week of treatment. This lady had used olz for at least six months, and the liver enzymes have since normalised.

Impairment of consciousness and cognitive functioning: The first remarkable feature of OLZ treatment was that, patients who experienced insomnia while on a combination of high dose classical neuroleptics, did sleep soundly on just $20 \mathrm{mg}$ olz nocte.

However, in the day time, they had clear consciousness and did not have the tired, day - time sommolent look that is characteristic of patients on high levels of neuroleptics. The subjects had high levels of concentration and attention in the day time. OLZ seemed to have beneficient effects on cognitive functioning on two schizophrenia - like cases with brain damage.

\section{DISCUSSION}

The cohort was typical of the broad range of severe mentally ill patients that we treat in our facility in Fiji, with a broad age range and diagnostic categories. In particular, the admixture of races in the sample is a fair representation of the multi- racial nature of the country. In addition, we had the opportunity to observe these patients for over a period of one year on follow up, several months after many of the subjects had stopped using the drug.

A major limitation of the study is that we were operating with serious constraints of drug supply. The situation of limitation of drug supply was even more problematic for the out-patients whose relatives bought the drug. The high purchasing cost of the drug was always a cause of complaints by these relatives. Other limitations are the small sample size and the open-label nature of the study which could lead to bias in ratings, especially as the same worker did all the assessments. In order to overcome this bias, data were presented to show actual clinical recovery (CGI).

Efficacy profiles: Clearly, OLZ was proven to be a highly potent antipsychotic drug among this cohort of patients with a wide variety of severe psychiatric conditions. Of particular interest is the finding that by the 8th week, 13 $(48.1 \%)$ of 27 long-stay neuroleptic treatment resistant patients achieved full clinical recovery (ie. CGI, 1 or 2), a finding comparable to the best clinical outcome noted for clozapine for a similar category of patients (19). A Spanish group (13), using efficacy indices of $\geq 35 \%$ decrease in symptoms and CGI severity $\leq 4$, in a trial of OLZ on 25 treatment refractory schizophrenics, found that $36 \%$ achieved this response at six weeks, and $48 \%$ at six months. All the symptoms of severe psychiatric states were beneficiently affected.

As far as this author is aware, this is one of the first reports of the efficacy of OLZ, specifically on depression and OCD.

The results of this study are in keeping with the findings of previous controlled studies. Since the findings of this study issue from a naturalistic clinical setting, the results are more likely to be in line with practical daily clinical experience. The open label nature of the study does not detract from the quality of the work, because majority of the patients acted as their own controls, since they had been on treatment with high dose neuroleptics for several years in hospital.

With the small number of OCD cases involved in this study, the effect of OLZ on this condition encourages a trial with a large sample size.

The efficacy of Olz in the treatment of depressive symptoms among schizophrenics has been examined in two controlled studies(3,7). Olz treated patients had significantly greater reduction in PANSS depression item and the Montgomery - Asberg Depression Rating Scale (MADRS), compared with schizophrenics treated with haloperidol and risperidone. The antidepressant effect was maintained during the subsequent maintainance period. Further proof of thymoleptic properties of Olz comes from studies of patients with schizoaffective disorder, psychotic depression and treatment - refractory depression $(11,12)$.

The wide ranging clinical effectiveness of OLZ is most probably explained by its pleotropic effect. For instance, the density of 5HT2A receptors has been reported to be increased among patients with major depression. Accordingly, OLZ, as a potent 5-HT2A antagonist, may have acted on these sites, similar to the action of a classical antidepressant such as nefazodone(20). The most interesting aspect of the antidepressant effect of OLZ is that it relieves depression at a median dose $(10 \mathrm{mg})$ much earlier than the classical antidepressant drugs. The mood related findings in this study are relevant because the classical neuroleptics rather tend to be depressogenic(3).

Safety profiles: The most relevant side effects of OLZ for this group of patients turned out to be weight gain and high purchasing cost. Otherwise OLZ achieved the distinction of being able to send severely disturbed patients to sleep at night, without a residue day-time drowsiness, impairment of cognitive functioning, and extrapyramidal reactions. As the study progressed the author gained the impression that OLZ is a fairly "clean" molecule among antipsychotic drugs. Also, cognitive function was rather enhanced, in line with the findings of a recent Canadian study in which olanzapine had a significantly superior beneficient effect on cognitive functioning among schizophrenics compared with risperidone and haloperidol(11).

In conclusion, with all these properties, OLZ, thus far, can be said to be a safe drug, which has merited the credentials of an "atypical" antipsychotic. An important experience gained from this study is that, no matter how effective a drug is in relieving symptoms, serious attention to psychosocial factors is crucial in the overall treatment outcome.

\section{ACKNOWLEDGEMENTS}

Dr. N. Goneyali, Mr. Abdul Azam and the Fiji Drugs and Therapeutics Review Committee, approved the purchase of 
olanzapine. The cooperation of the clinical staff at St. Giles Hospital, is appreciated. Dr. Rajan Singh took blood samples. Salote Cavakilagi. I first became aware of Olanzapine through Mr. Riaz Buksh of Eli Lilly and Co. David Saunders for computer analysis for secretarial services.

\section{REFERENCE}

1. Hegarty J.D., Baldessarini R.J., Tohen M., Watemaux, C. and Oepan G. One hundred years of schizophrenia: a meta analysis of the outcome literature. Amer. J. Psychiat. 1994; 151:14091416.

2. Gerlach J. and Peacock L. New antipsychotics: The present status. Int. Clin. Psychopharm. 1995, 10 (suppl 3), 39-48.

3. Tollefson G.D., Beasley C.M. and Tran P.V. Olanzapine versus haloperidol in the treatment of schizophrenia and schizoaffective and schizophreniform disorders. Results of an International Collaborative Trial. Amer. J Psychiat. 1997; 154: 457 - 465.

4. Moore, N.A., Tye, N.C., Axton M.S. and Risins F.C. The behavioural pharmacology of olanzapine, a novel "atypical" antipsychotic agent. J. Pharm. Experim. Therapeu. 1992; 262: 545 - 551.

5. Tollefson, G.D. and Sanger, T.M. Negative Symptoms: A path analytical approach to a double-blind, placebo-and haloperidol - controlled clinical trial with olanzapine. Amer. J. Psychiat. 1997; 154: 466- 474

6. Beasley, C.M., Tollefson G. and Tran, P.V. Efficacy of Olanzapine: An overview of pivotal clinical trials. J. Clin Psychiat. 1997; 58 (suppl 10):7- 17.

7. Tran, P.V., Hamilton, S.H., Kuntz, A.J. et.al. Double-blind comparison of olanzapine versus Risperidone in the treatment of schizophrenia and other psychotic disorders. J. Clin. Psychopharmacology, 1997; 17: 407 - 418.

8. Hamilton, S.H., Revicki, D.A., Genduso, L.A. and Beasley, C.M. Olanzapine versus placebo and haloperidol: Quality of life and efficacy results of the North American Double-Blind Trial. Neuro-psychopharmacology, 1998; 18: 41-49.

9. Arnt, J. and Skarsfeldt, T. Do novel antipsychotics have similar pharmacological characteristics? A review of the evidence. Neuropsychopharmacology. 1998; 18:63-101.

10. Sanger, T.M., Tohen, M., Tollefson, G.D., McElroy, S.L., Greany, M.G. and Toma, V. Olanzapine Vs Placebo in the treatment of acute mania. Schizophr Res. 1998; 29:152.

11. Shelton, R., Tollesfson, G. and Tohen, M. The study of olanzapine versus fluoxetine in treatment - resistant major depressive disorder without psychotic features. In: Abstracts of the NCDEU Annual Meeting. Boca Raton, Fluorida; NCDEU, 1998.

12. Weisler, R.H., Ahearn, E.P. and Davidson, J.R.T. Adjunctive use of olanzapine in mood disorders: five case reports. Ann Clin Psychiat. 1997; 9: 259-262.

13. Sacristan, J.A., Gomez, J.C., Martin J., Garcia-Bemado E., Peralta V., Alvarez, E. and Gurpegni, M. Pharmacoeconomic assessment of olanzapine in the treatment of refractory schizophrenia based on a pilot clinical study. Clin Drug Invest, 1998; 15:29-35.

14. Launer, M.A. High dose olanzapine in treatment resistant schizophrenia. Schizophr Res. 1998; 29:149.

15. Kay, S: The Positive and Negative Syndrome Scale (PANSS) for Schizophrenia. Schizophr Bull. 1987; 13: 262-273.

16. Guy, W. (ed): ECDEU Assessment Manual for Psychopharmacology. Publication ADM 76-338, Rockville, Md, US Department of Health, Education and Welfare, 1976; 217-222.

17. Simpson, G.M. and Angus, J.W. A rating scale for extrapyramidal side effects. Acta Psychiatrica Scand, 1970; suppl. 21 2:11 - 19 .

18. Barnes, T.R.E. A rating scale for drug induced akathesia. Brit. $J$ Psychiat. 1989; 154: 672 - 676.

19. Meltzer, H.Y. Treatment of the neuroleptic-noresponsive schizophrenic patients. Schizophr Bull, 1992; 18: 515-542.

20. Nemrick-Lueche, S.K., Snoddy, H.D. and Fuller, R.W. Evaluation of nefazodone as a serotonin uptake inhibitor and a serotin antagonist in vivo. Life Science. 1994; 55:479-483. 